\title{
Three-dimensional simulation of ship bow slamming
}

\author{
Li sha $\mathrm{Gao}^{1}$, Pan $\mathrm{Zhou}^{2, *}$ \\ ${ }^{1,2}$ Wenhua College, Wuhan,430074, China
}

\begin{abstract}
The bow flare slamming load was studied by using the software Ls-dyna. A coupling finite element model including air, water and $3 \mathrm{~d}$ bow was established. Flare slamming pressure was picked up from the finite element model in order to discuss the relation between flare slamming pressure and the velocity as well as the distribution rule of slamming pressure in different velocity and different water entry angle along the length and height of the ship.
\end{abstract}

\section{Numerical simulation of three-dimensional bow slamming}

Slamming is a highly non-linear phenomenon caused by the interaction between the moving hull and the waves. Generally, there are three types: bottom slamming, floating slamming and upper wave slamming. Floating slamming is a phenomenon in which a large impulse hydrodynamic force is often generated when a wave impacts the floating area of the bow when a ship is moving at sea, which causes a sudden change in the acceleration of the hull. Outward slamming is affected by many factors, such as wave characteristics, ship motion, and bow linearity. Usually container ships, aircraft carriers and other ships with large bows, need to consider the threat of floating slamming. For example, in the North Pacific close to Japan, due to the monsoon from the west, it is usually in rough seas in winter. Container ships sailing from North or South America to Japan are often damaged by floating slamming ${ }^{[1]}$.

\subsection{Software description}

Ls-dyna is the world's most famous general-purpose explicit dynamic analysis program. It can simulate various complex problems in the real world. It is especially suitable for solving various two-dimensional and three-dimensional nonlinear structures such as high-speed collisions, explosions, and metal forming nonlinear dynamics. Impact problems can be solved at the same time as heat transfer, fluid and fluid-solid coupling problems. It is widely recognized as the best analysis software package in the engineering application field. Numerous comparisons with experiments have confirmed the reliability of its calculations. Ls-dyna is mainly based on Lagrange algorithm, combined with ALE and Euler algorithms ${ }^{[2]}$.

\subsection{Simulation calculation model}

River-to-sea direct ships are ships that can navigate both inland rivers and coastal navigation areas. In order to increase the cargo capacity of ships, many river-to-sea direct ships use the form of container ships, and the first part has a large drift. Using Ls-dyna display dynamic analysis software, according to a 1:1 ratio, select a river-sea direct ship from the 155th frame to the bow to establish a three-dimensional hull simulation model. The design draft of the ship is $5.5 \mathrm{~m}$.

Place the model in a water area of $100 \mathrm{~m} \times 80 \mathrm{~m} \times 60 \mathrm{~m}$ and an air area of $100 \mathrm{~m} \times 80 \mathrm{~m} \times 20 \mathrm{~m}$. The fluids (water and air) all adopt the Gruneisen equation of state, and the model is regarded as a rigid body. Table 1 is the parameter table of the state equation of water and air. The Gruneisen equation of state incorporates the tertiary impact velocity - the particle velocity, which defines the compressed material pressure in air and water as:

$$
P=\frac{\rho_{0} \mathrm{C}^{2} \mu\left[1+\left(1-\frac{\gamma_{0}}{2}\right) \mu-\frac{\mathrm{a}}{2} \mu^{2}\right]}{\left[1-\left(\mathrm{S}_{1}-1\right) \mu-\mathrm{S}_{2} \frac{\mu_{2}}{\mu+1}-S_{3} \frac{\mu^{3}}{(\mu+1)^{2}}\right]^{2}}+\left(\gamma_{0}+a \mu\right) E
$$

Among them: $\mathrm{C}$ is the impact speed; $\mu_{\mathrm{z}}$ is the intercept of the particle velocity $\mu_{\mathrm{p}}$; a is the first-order volume correction to $\gamma_{0} ; S_{1}, S_{2}, S_{3}$ are corrections to the slope of the $\mu_{z}-\mu_{p}$ curve; $E$ is the initial internal energy;

Define compression state with relative volume:

$$
\mu=\frac{1}{V}-1
$$

$\mathrm{V}$ is the initial relative volume; The particle velocity $\mu_{\mathrm{p}}$ is related to the impact velocity $\mu_{\mathrm{s}}$ using the following formula.

$$
\mu_{s}=C+S_{1} \mu_{p}+S_{2}\left(\frac{\mu_{p}}{\mu_{s}}\right)^{2} \mu_{p}+S_{3}\left(\frac{\mu_{p}}{\mu_{s}}\right)^{3} \mu_{p}
$$


Table 1. Parameter table of water and air state equation

\begin{tabular}{|c|c|c|c|c|}
\hline Name & $\rho /\left(\mathrm{kg} / \mathrm{m}^{3}\right)$ & $\mathrm{C} /(\mathrm{m} / \mathrm{s})$ & $\mathrm{S}_{1}$ & $\mathrm{~S}_{2}$ \\
\hline Water & 1025 & 1480 & 1.29 & -0.096 \\
\hline Air & 1.29 & 340 & 0 & 0 \\
\hline
\end{tabular}

The water and air are modeled by Euler grids, and the unit uses the single-point integration multi-material ALE algorithm; the structural model is modeled by Lagrange grids. The ALE general coupling algorithm is used between the structure and the fluid, and the interface between the structure and the fluid is defined as a fluid-solid coupling surface. The grids of the air and water areas are divided according to the unequal density grids that are dense in the center, and the air and water areas close to the model are denser. Non-reflective boundary conditions are used around the air and water areas. The coordinate axis adopts the right-hand rule, along the ship's length direction as the $\mathrm{x}$ axis, along the height direction as the y axis, and along the ship width direction as the $\mathrm{z}$ axis. The structure model is placed in the water area with a design draft of $5.5 \mathrm{~m}$. The overall model is shown in Figure 1, the air area and water area are shown in Figure 2, the blue area is the air area, the red area is the water area, and the structure model is shown in Figure 3.

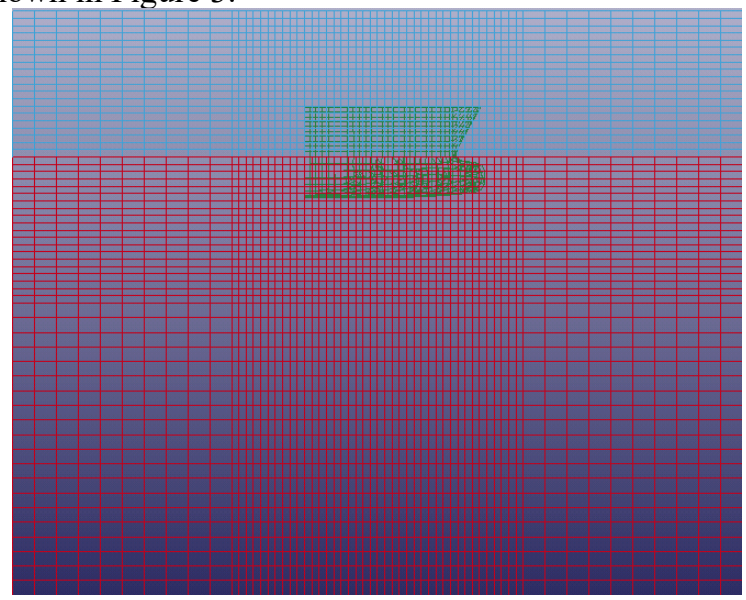

Fig. 1. Overall model

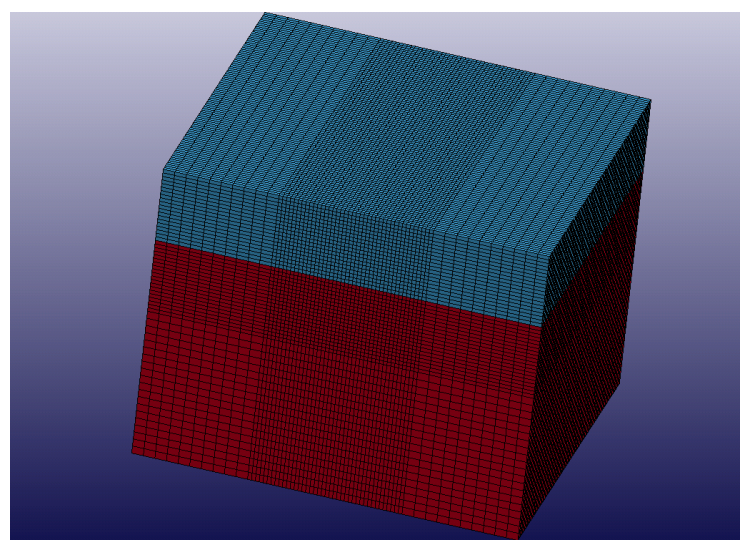

Fig. 2. Air and water model

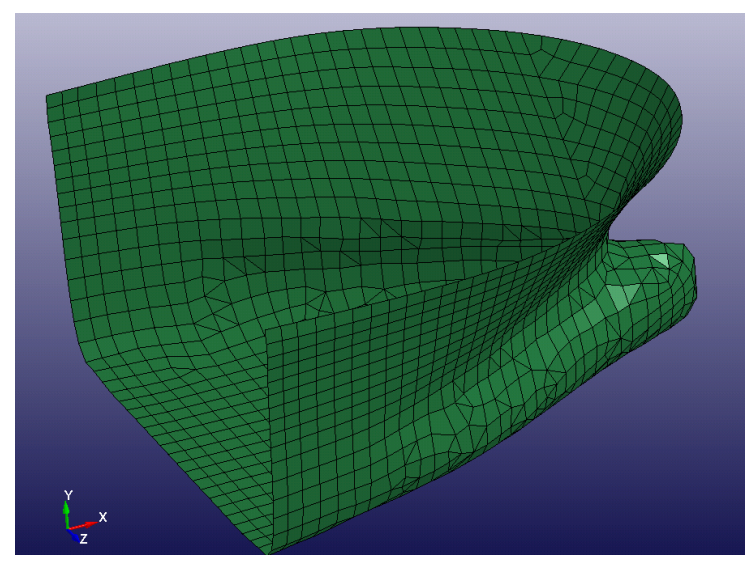

Fig. 3. Structure model

\section{Analysis of the slamming pressure law of the bow floating}

\subsection{The structure enters the water vertically}

The slamming pressure of the bow is mainly composed of two parts. One is the water entry pressure Pi between the impact surface and the wave caused by the normal component of the relative velocity between the hull and the wave on the water surface; the other is the relative velocity between the hull and the wave. The impact pressure Ps between the impact surface and the water mass point caused by the tangential component of the water surface. The impact pressure is much smaller than that of the water. Now let the structure model enter the water vertically at a speed of $5 \mathrm{~m} / \mathrm{s}, 6 \mathrm{~m} / \mathrm{s}$, and $7 \mathrm{~m} / \mathrm{s}$. Figure 4 shows the spray caused by the structure model entering the water vertically at a speed of $7 \mathrm{~m} / \mathrm{s}$ when $\mathrm{t}=0.6 \mathrm{~s}$.

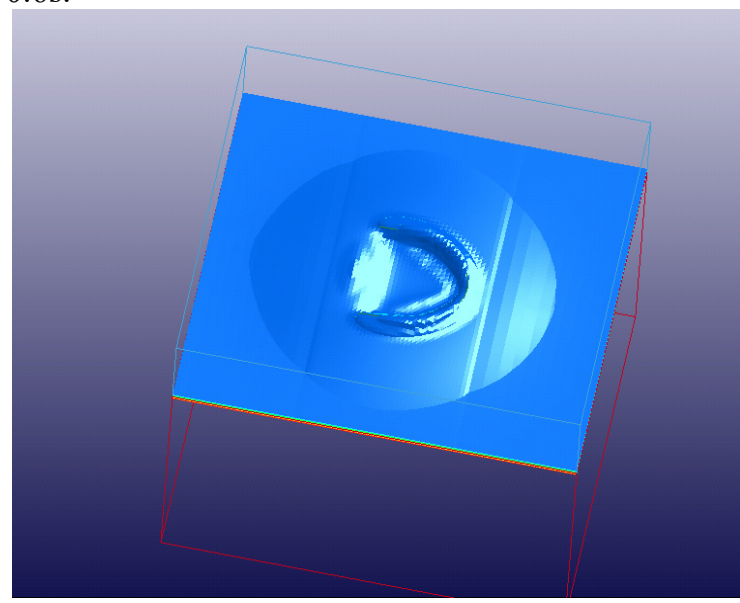

Fig. 4. The structure enters the water vertically at $7 \mathrm{~m} / \mathrm{s}$

\subsubsection{The relationship between floating slamming pressure and speed}

The schematic diagram of the slamming pressure calculation point of the finite element model is shown in Figure 5. 


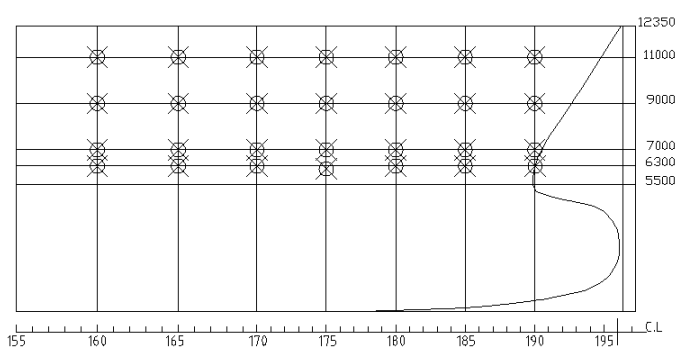

Fig. 5. Schematic diagram of the slamming pressure calculation point of the finite element model

Taking the peak slamming pressure at the No.170 rib position of the structural model and comparing the peak slamming pressure at the points $7 \mathrm{wl}, 9 \mathrm{wl}$, and $11 \mathrm{wl}$ with the square of the water entry speed, it can be seen that the peak slamming pressure is basically in a linear relationship. The relationship between the peak slamming pressure and the square of the velocity is shown in Figure 6.

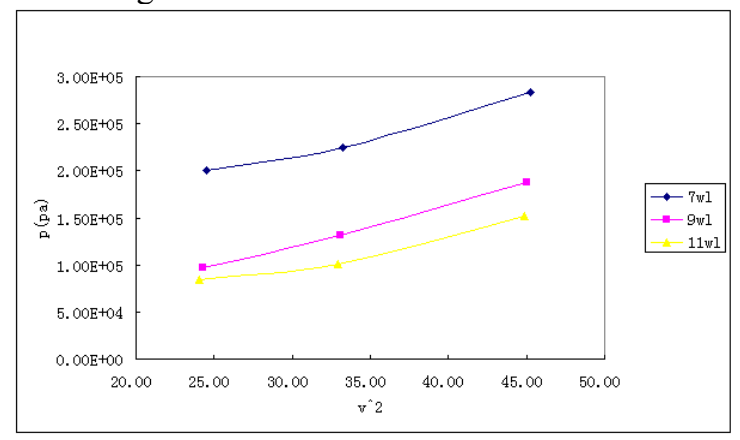

Fig. 6. The relationship between the peak slamming pressure and the square of the water entry velocity

\subsubsection{Distribution law of floating slamming pressure along the ship's length}

Figure 7 shows the variation of the slamming pressure at each rib at $6.3 \mathrm{wl}, 7 \mathrm{wl}, 9 \mathrm{wl}$, and $11 \mathrm{wl}$ when the model enters the water vertically at $7 \mathrm{~m} / \mathrm{s}$.

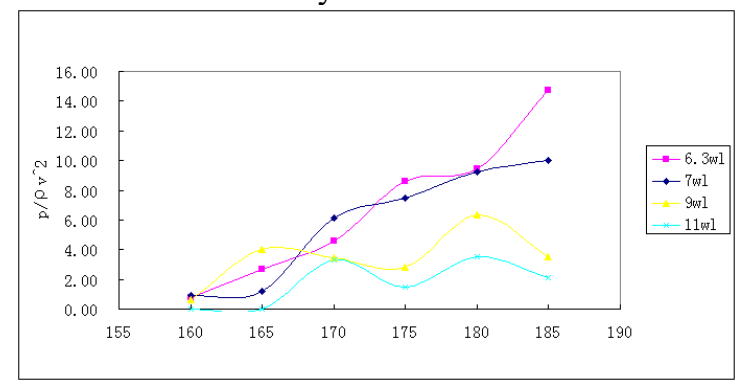

Fig. 7. The distribution of slamming pressure along the ship's length

It can be seen from the above figure that along the length of the ship, the slamming pressure changes roughly from the No. 160 rib to the No.185 rib. The closer to the bow, the greater the slamming pressure.

\subsubsection{Distribution law of floating slamming pressure along the height direction}

Figure 8 shows the structure model with $7 \mathrm{~m} / \mathrm{s}$ vertical water entry, from the No. 170 rib position to the No. 185 rib position, and the distribution law of each rib position along different water lines.

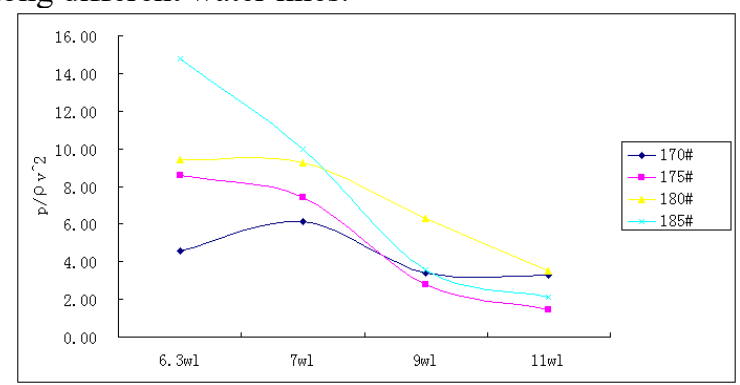

Fig.8.Distribution law of floating slamming pressure along the height direction

It can be seen from the above figure that the slamming pressure is along the height direction, and the closer to the design draft, the greater the slamming pressure. The slamming pressure at each point of rib 185 near the bow varies greatly. The slamming pressure at the point close to the design draft is greater than the slamming pressure at the point far away from the design draft.

\subsection{Structure oblique to water}

In order to better simulate the effect of the slamming pressure of the ship in the waves, the structure model is now placed on the water surface obliquely. Since the river-to-sea direct ship mainly sails in the E1 sea area, the statistical data shows that the significant wave height in the E1 sea area is $6 \mathrm{~m} \sim 7.5 \mathrm{~m}$, and the average zero-crossing period is $8 \mathrm{~s} \sim 10 \mathrm{~s}$. From this, we can get the steep wave under dangerous conditions. size. Therefore, the model is rotated by $5^{\circ}, 10^{\circ}, 15^{\circ}$, and $20^{\circ}$ to compare the slamming pressure at different angles at the same speed $(5 \mathrm{~m} / \mathrm{s})$.

\subsubsection{Calculation model}

The structure model is $20^{\circ}$ with the water surface as shown in Figure 9. When $\mathrm{t}=0.6 \mathrm{~s}$, the splashes aroused are shown in Fig. 10.

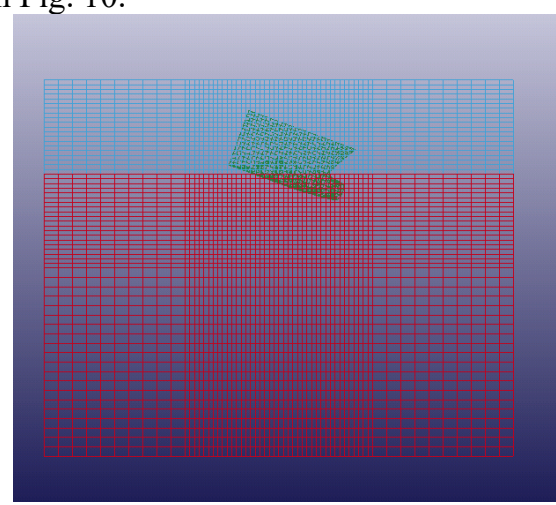

Fig. 9. The structure model is $20^{\circ}$ to the water surface 


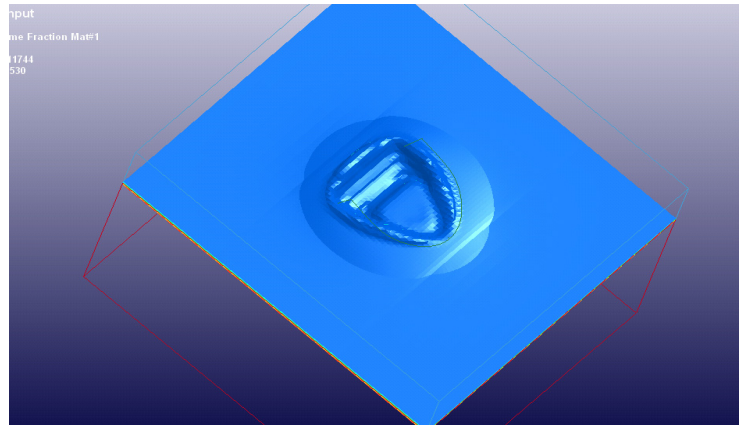

Fig. 10.The structure and the water surface are at $20^{\circ}$ to arouse spray

\subsubsection{Analysis of the law of slamming pressure from different angles along the length of the ship}

Under different angles, the change of the slamming pressure of the bow floating at each point of $7 \mathrm{wl}$ and $9 \mathrm{wl}$ is shown in Figure 11 and Figure 12.

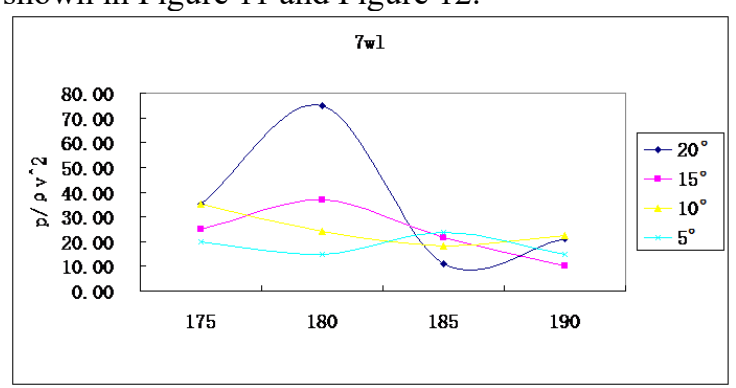

Fig. 11.Slamming pressure changes at various points along the $7 \mathrm{wl}$ at different angles

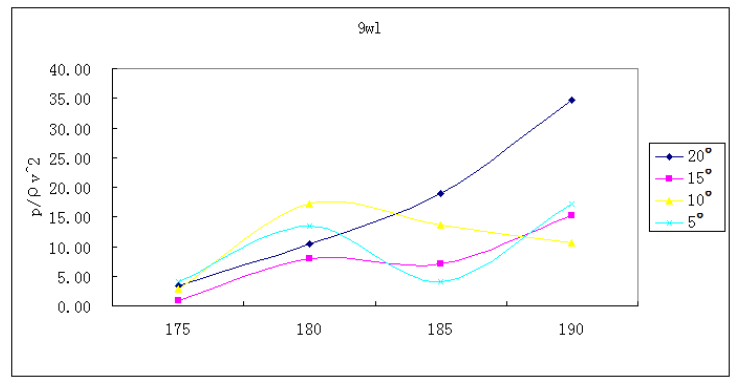

Fig. 12. Slamming pressure changes at various points along the $7 \mathrm{wl}$ at different angles

It can be seen from the figure that the slamming pressure of the outer float is roughly the same along the length of the ship under different angles. The larger the angle, the greater the slamming pressure. When the bow is inclined to 20 degrees, at $7 \mathrm{wl}$, the slamming pressure varies greatly.

\subsubsection{Analysis of the law of slamming pressure along the height direction from different angles}

When the model enters the water at the same speed and at different angles, the slamming pressure curve at the No. 175 rib position and the No. 180 rib position are shown in Figure 13 and Figure 14.

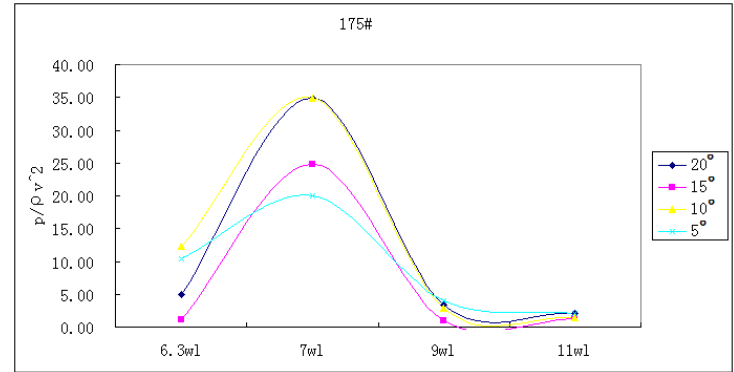

Fig. 13. Changes in slamming pressure at various points along the No.175 rib at different angles

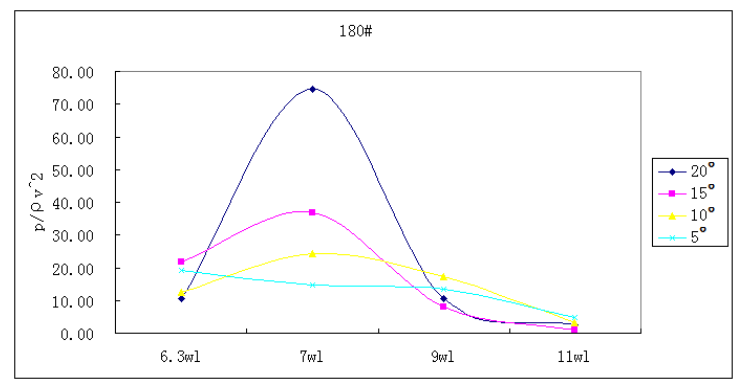

Fig. 14. Changes of slamming pressure at each point of the No.180 rib position at different angles

It can be seen from the figure that the external slamming pressure is roughly the same along the height direction under different angles. The larger the angle, the greater the slamming pressure. When the bow is inclined to 20 degrees, the slamming pressure varies greatly along the NO.180 rib.

\section{Conclusion}

Floating slamming pressure is a non-linear problem with a certain degree of complexity. At present, there are few domestic literatures on floating slamming pressure. Some articles are based on probability stochastic theory to study the floating slamming characteristics of the side of a container ${ }^{[3]}$. The article studies the probability distribution of the effective slamming angle of the ship drifting $^{[4]}$. In this paper, using Ls-dyna software, considering the effect of fluid-structure interaction, the floating slamming pressure at each point is obtained, and the following conclusions are obtained:

-With the increase of speed, the outward slamming becomes bigger and bigger, and the slamming pressure is proportional to the water entering speed at each point.

-Outer drift slamming decreases with the increase in height. Near the design draft, the outer drift slamming is larger.

-Along the length of the ship, near the bow of the ship, the outward slamming is generally larger.

As the angle of entry into the water changes, the drifting slamming will change. Generally, the greater the angle of entry, the greater the drifting slamming will be. 


\section{References}

1. Dai Yangshan, Shen Jinwei, Song Jingzheng. Ship wave load[M]. Beijing: National Defense Industry Press, 2007.

2. Shi Dangyong, Li Yuchun, Zhang Shengmin. Display dynamic analysis based on ANSYS/LS-DYNA $8.1 \quad$ [M]. Beijing: Tsinghua University Press, 2005.
3. Chen Zhen, Feng Yongjun, Xiao Xi. Research on slamming characteristics of large container ship side $\operatorname{drift}[J]$. Ship and Ocean Engineering, 2011, 40(3):1-4.

4. Chen Zhen, Zhang Shilian, Xiao Xi. Probability distribution of effective slamming angle for ship drifting outside [J]. Journal of Shanghai Jiaotong University. 2010.44(10); 1405-1408. 